psychiatric patients as about the same as that in the general population and noted that it accounted for less than $1 \%$ of psychiatric illness. He suggested that the psychiatrist should be alert to the possibility of vitamin $B_{12}$ deficiency in three situations: patients thought to be at risk clinically-for example, anaemic or post-gastrectomy patients-patients with unexplained fatigue, and patients with confusional states or dementia of unknown origin. Some screening tests must be employed, since vitamin $B_{12}$ deficiency, however manifested, is treatable and early diagnosis is essential.

In most patients with mental symptoms due to vitamin $B_{12}$ deficiency changes will be found in the peripheral blood or the bone marrow. The haemoglobin estimation, a full blood count, and a film must be checked and the blood film must be seen by an expert haematologist. Evidence of macrocytosis or of hypersegmentation of nuclei of the leucocytes indicates that estimation of serum $B_{12}$ and folate levels should be performed. If any neurological abnormalities were discovered, such as peripheral neuropathy or signs of subacute combined degeneration, then regardless of the haematological findings the serum $B_{12}$ and folate estimations should be made. In general practice little guidance can be expected from the results of the gastric parietal cell antibody test in the elderly, since antibodies to gastric parietal cells are not present in all patients with pernicious anaemia, and many false positive results will be found.

Dementia due to folate deficiency should be considered if an elderly, mentally disturbed patient has a history suggestive of nutritional deficiency. Such a person would almost certainly belong to a high-risk group-he might be depressed and apathetic, perhaps recently bereaved, or mildly confused, with the probability of bad food habits; the vital factor is probably the intake of vegetables. There might be a history of increasing lassitude, apathy, and weakness. In such cases, as well as full haematological investigation, serum levels of vitamin $B_{12}$ and folate would have to be estimated. Ascorbic acid deficiency may coexist, but its confirmation requires determination of the corrected leucocyte ascorbic acid levela test not generally available at present.

Potassium deficiency is apt to occur in the type of patient described above. The elderly require about $50 \mathrm{mEq}$ of potassium per day, and patients taking less are prone to muscle weakness, apathy, depression, and faecal impaction. In patients with a marginal potassium intake deficiency can be produced rapidly by diuretic therapy and is often complicated by digitalis intoxication. ${ }^{7}$

The rare finding in the disturbed patient of an abnormal level of calcium in the blood at present serves only to complicate the elucidation of an already intricate and complex symptom. ${ }^{8}$

Interesting facts ${ }^{910}$ are gradually emerging about the nutrition of older people and everyone is anxious to diagnose remediable mental illness. In clinical practice, deficiencies of food factors occurring in the elderly are commonly multiple, and therapy is not usually adequate if one specific

\footnotetext{
Anderson, W. F., Practical Management of the Elderly, 1967. Oxford, Blackwell Scientific Publications.

Andrews, J., Letcher, M., and Brook, M., British Medical fournal, $1969,2,416$.

Strachan, R. W., and Henderson, J. G., Quarterly fournal of Medicine, $1965,34,303$.

Strachan, R. W., and Henderson, J. G., Quarterly Fournal of Medicine, 1967, 36, 189.

Murphy, F., Srivastava, P. C., Varadi, S., and Eluris, A., British Medical fournal 1969,359

Shulman, R., British Medical fournal, 1967, 3, 266.

Judge, T. G., Medical News, 1969, No. 345, p. 6.

British Medical fournal, 1968, 2, 5

- British Medical fournal, 1969, 2, 396.
}

substance alone is supplied. However, the common causes of mental confusion are not of dietetic origin. In cases where the possibility of deficiencies of an essential nutriment comes to mind, from the dietetic history, the past story of gastrectomy, or the mental and social state of the patient, then the exclusion of lack of vitamin $B_{12}$, folic acid, potassium, and vitamin $C$ must be considered.

\section{No Cell is an Iland Intire of It Selfe}

The breakdown of the idea that the mammalian cell is a selfcontained unit is bringing excitements almost every week in the fields of biology and cancer research. Now L. F. Watkins and L. Chen from the Sir William Dunn School of Pathology in Oxford report that hybrid cells formed by the fusion of a malignant cell from a mouse with a hamster cell transformed by virus infection can immunize mice against the growth of tumours from the parent mouse cells. ${ }^{1}$ It opens up a new approach to the treatment of cancer in man by means of immunity mechanisms, reviewed recently by G. Hamilton Fairley. $^{2}$ Watkins and Chen suggest that the hybrid cell they studied " is analogous to an attenuated tumour cell."

Until recently the assumption that each mammalian cell has an individuality-a structural and functional sanctity of its own-has not been seriously challenged. The general concept has been that every normal body cell has in its deoxyribosenucleic acid (D.N.A.) all the information required to produce the whole organism, most of it in a suppressed state. Malignant cells are supposed to be derived from normal cells by loss of essential information, by gain of rogue information, or by an unfavourable mutation, or change, of that information. Restoration from rogue state to normal state through the operation of repair mechanisms is being studied, ${ }^{34}$ but there is so far little evidence that such restoration is possible in the case of highly malignant and rapidly proliferating tumour cells. In any case "repair" has been thought of as an essentially intracellular process, and the possibility that unaffected normal cells might restore damaged cells to a normal structure, or at least normal behaviour, by donating nucleic acids or other cell components has received little serious attention.

In 1960 G. G. Rose ${ }^{5}$ reported the demonstration by timelapse photography of what he interpreted as " mitochondrial migration between closely related cells" and the transfer of various cell organelles between cells by cytoplasmic fragmentation and the resorption of the free fragments by neighbouring cells. Also in 1960 G. Barski, S. Sorieul, and F. Cornefert $^{6}$ detected hybrid cells in mixed cultures of mouse

Watkins, L. F., and Chen, L., Nature, 1969, 223, 1018.

Fairley, G. H., British Medical fournal, 1967, 2, 467.

Roberts, J. J., Crathorn, A. R., and Brent, T. P., Nature, 1968, 218, 970.

Painter, R. B., and Cleaver, J. E., Nature, 1967, 216, 369.

Rose, G. G., Texas Reports on Biology and Medicine, 1960, 18, 103.

Barski, G., Sorieul, S. and Cornefert, F., Comptes Rendus Hebdomadaires des Séances de l'Académie des Sciences, 1960, 251, 1825. daires des Séances de l'Academie des Sciences, 1960, 251, 1825.
Barski, G., and Cornefert, F., fournal of the National Cancer Institute, $1962,28,801$.

Defendi, V., Ephrussi, B., Koprowski, H., and Yoshida, M. C., Proceedings of the National Academy of Sciences of the United States of America, 1967, 57, 299.

- Spencer, R. A., Hauschka, T. S., Amos, D. B., and Ephrussi, B., Fournal of the National Cancer Institute, 1964, 33, 893.

10 Harris, H., and Watkins, J. F., Nature, 1965, 205, 640

1 Harris, H., Miller, O. J., Klein, G., Worst, P., and Tachibana, T., Nature, 1969, 223, 363 . 
tumour cells of high and low malignancy. The hybrid cells had certain structural, chromosomal, and biological characteristics of both parental cell lines, but resembled the more malignant parent strain in respect of malignant behaviour. ${ }^{7}$ This work and other work $^{8}$ suggested that malignancy is a dominant characteristic, and that hybrid cells express the histocompatibility antigens of both parents, neither being suppressed. ${ }^{9}$

The observation ${ }^{10}$ that hybrids can be formed from virtually any two cells of mammalian origin by the introduction into mixed cell cultures of inactivated Sendai virus made feasible a more extensive study of cell hybridization, and Henry Harris and O. J. Miller from Oxford and George Klein, P. Worst, and T. Tachibana from Stockholm, in a joint paper, ${ }^{11}$ have recently reported the extremely interesting and important observation that the malignant behaviour of mouse cancer cells may be suppressed by fusing them with a particular line of non-malignant cells known as the A9 line. The authors describe three examples of such suppression. In each case the resultant hybrids were generally stable with respect to chromosome number and other characteristics, but in a few instances subsequent loss of chromosomes was associated with reversion to malignant behaviour. These observations justify the view that the phenomenon should be regarded as suppression of malignancy rather than as repair or restoration of normality.

Harris and Klein and their colleagues ${ }^{11}$ also report suppression in one of the types of hybrid cell they studied of histocompatibility antigens, though the antigens suppressed were those of the A9 cell and not those of the malignant cell with which it was fused.

The possibilities that use can be made of these discoveries in the treatment of malignant disease or to reduce the antigenicity of tissues to be used as transplants are exciting, though years of patient research may be needed before suitable methods are developed. In the meantime the mechanisms involved will be the object of thorough study by numerous investigators.

\section{Medical Contributions to Suicide}

Some of those who commit or attempt suicide are under medical care at the time. The proportion is highest among the psychiatrically ill. The suicide rate among patients in mental hospitals in Britain has been found to be four to five times as high as among the general population. ${ }^{1}$ All this is not surprising, since psychiatric patients as a group are known to be excessively suicide prone. It is often suggested that the incidence of suicidal acts among them would be even higher were it not for the medical care they receive. These apparently unassailable assumptions have recently been questioned" at a conference on "Iatrogenic Disease and Medical Experimentation" held by the Medical Association of New

Stengel, E., and Cook, N. G., Attempted Suicide, 1958. London, Oxford University Press.

2 Ironside, W. New Zealand Medical fournal, 1969, 69, 207

3 Flood, R. A., and Seager, C. P., British fournal of Psychiatry, 1968 114, 443

4 British Medical fournal, 1964, 2, 789.

5 Balint, M., The Doctor, His Patient and the Illness, 1964, 2nd ed. London, Pitman Medical.

- Stengel, E., Suicide and Attempted Suicide, 1969, revised ed. London, Penguin Books.
Zealand. In a discussion of the harm doctors can do, it was quite legitimate to ask why so many patients under medical care committed suicidal acts and whether there was not an iatrogenic contribution to this dismal record ?

A group of 35 psychiatric patients admitted to an inpatient unit after a suicidal attempt were studied. At the time of the attempt 24 were under medical care, and 19 used drugs prescribed by their doctors. It was found that the hostile, demanding, depressed patient of low and devalued social status tended to be rejected by the doctor, who would terminate treatment prematurely and thus increase the risk of suicide. R. A. Flood and C. P. Seager ${ }^{3}$ had made similar observations at Bristol. It seems that, in this area at least, doctors tend to discriminate against those whose behaviour does not fit with their (unconscious) image of the model patient who is physically ill, passive, appreciative, and grateful, especially if he is not middle class. Furthermore, the tendency to reject the patient whom he dislikes may cause the doctor to over-prescribe for him rather than to give more of himself, thus unwittingly colluding with the patient's wish to die. But, according to Professor W. Ironside, the psychology of interpersonal relations between the unwanted patient and his doctor is even more complicated. The doctor, having been antagonized by the patient, feels rejected himself and reacts with depression, which he tends to project on the patient together with the suicidal impulse. All these largely unconscious psychological processes can distort clinical judgement, with a resulting potentiation of the suicidal risk. They are also supposed to be partly responsible for the excessive suicide rate among doctors ${ }^{4}$ and especially among psychiatrists. Ironside stresses the need for doctors to be made aware of their own psychological reactions to patients with the help of training methods such as those advocated by $M$. Balint. ${ }^{5}$

Speculative though some of Ironside's notions are, there is much evidence that many doctors tend to underrate and deny the risk of suicide in their patients. This tendency, which they share with the lay public, can be best countered by the study of the motivations to suicidal acts, which are much more complex than the average layman and many doctors believe them to be. ${ }^{6}$ Too often attempts at suicide are dismissed as nothing but gestures by people who wish to draw attention to themselves. The notion that the truly suicidal person must address himself to death alone dies hard. In fact, there is much evidence that "most people who commit suicidal acts, fatal or non-fatal, do not either want to die or to live but they want to do both at the same time, usually the one more, or much more, than the other." ${ }_{6}$

\section{Practical Neurology}

This week we start publication of a series of articles on the management of some common neurological disorders. Neurology is sometimes regarded as a difficult, intellectual branch $\stackrel{\odot}{\Phi}$ of medicine; but strokes, Parkinsonism, migraine, and $\stackrel{\mathbb{Q}}{\varrho}$ epilepsy are seen in every general practice, and the care of $\bar{\sigma}$ these patients is a practical clinical problem. The emphasis $\delta$ of these articles will be on treatment and on advice to patients and their relatives. Though curative treatment is available for very few neurological diseases, much can be done to ease $\rightleftharpoons$ and comfort those who suffer from them. ,}

